\title{
Unlayered-Layered Crystal Transition in Recyclable Long-Spaced Aliphatic Polyesters
}

\author{
Stephanie F. Marxsen ${ }^{1}$, Manuel Häußler ${ }^{2}$, Stefan Mecking ${ }^{2}$, Rufina G. Alamo ${ }^{1 *}$ \\ ${ }^{1}$ FAMU-FSU College of Engineering, Department of Chemical and Biomedical Engineering, \\ 2525 Pottsdamer St, Tallahassee, FL, 32310 \\ ${ }^{2}$ Department of Chemistry, University of Konstanz, Universitätsstraße 10, 78457 Konstanz, \\ Germany
}

\section{Supporting Information}

Table SI.1. Molar mass and thermal characterization of long-spaced aliphatic polyesters.

\begin{tabular}{c|cccccc} 
Sample & $\begin{array}{c}\text { ester groups } \\
\text { per 100 methylenes }\end{array}$ & $\begin{array}{c}M_{w} \\
(\mathrm{~kg} / \mathrm{mol})\end{array}$ & $M_{\mathrm{w}} / M_{\mathrm{n}}$ & $\begin{array}{c}T_{\mathrm{c}} \\
\left({ }^{\circ} \mathrm{C}\right)^{\mathrm{c}}\end{array}$ & $\begin{array}{c}T_{\mathrm{m}} \\
\left({ }^{\circ} \mathrm{C}\right)^{\mathrm{c}}\end{array}$ & $\begin{array}{c}\Delta H_{\mathrm{m}} \\
(\mathrm{J} / \mathrm{g})^{\mathrm{c}}\end{array}$ \\
\hline PE-18,18 & 5.9 & $90^{\mathrm{a}}$ & 1.9 & 85.6 & 97.8 & 143 \\
PE-19,19 & 5.6 & $38^{\mathrm{b}}$ & 2.0 & 86.5 & 98.4 & 126 \\
PE-32,32 & 3.2 & $77^{\mathrm{b}}$ & 2.5 & 99.8 & 110.9 & 160 \\
PE-48,48 & 2.1 & $26^{\mathrm{b}}$ & 1.9 & 108.8 & 117.8 & 180
\end{tabular}

${ }^{a}$ Determined by GPC at $160{ }^{\circ} \mathrm{C}$ in 1,2-dichlorobenzene against polyethylene standards. ${ }^{\mathrm{b}}$ Determined by GPC at $160{ }^{\circ} \mathrm{C}$ in 1,2,4-trichlorobenzene against polyethylene standards. ${ }^{\mathrm{c}}$ Highest crystallization peak $\left(T_{\mathrm{c}}\right)$, highest melting peak $\left(T_{\mathrm{m}}\right)$, and observed total heat of fusion $\left(\Delta H_{\mathrm{m}}\right)$ obtained by DSC at $10^{\circ} \mathrm{C} / \mathrm{min}$.

*Corresponding author (alamo@eng.famu.fsu.edu) 
Table SI.2. $1^{\text {st }} 2^{\text {nd }}$, and $3^{\text {rd }}$ order long period peak locations and corresponding distances from SAXS of long-spaced aliphatic polyesters

\begin{tabular}{cc|ccc|ccc}
\multirow{2}{*}{ Sample } & $T\left({ }^{\circ} \mathrm{C}\right)$ & \multicolumn{3}{|c|}{ Peak Positions $\left(\AA^{-1}\right)$} & \multicolumn{3}{c}{ Long Period $(\AA)$} \\
& & $1^{\text {st }}$ Order & $2^{\text {nd }}$ Order & $3^{\text {rd }}$ Order & $1^{\text {st }}$ Order & $2^{\text {nd }}$ Order & $3^{\text {rd }}$ Order \\
\hline PE-18,18 & $0^{\text {a }}$ & 0.046 & - & - & 135 & - & - \\
& $87^{\mathrm{b}}$ & 0.037 & 0.087 & - & 172 & 72 & - \\
& $90^{\mathrm{c}}$ & 0.032 & 0.073 & 0.122 & 199 & 86 & 52 \\
\hline PE-19,19 & $0^{\text {a }}$ & 0.043 & - & - & 147 & - & - \\
& $88^{\mathrm{b}}$ & 0.034 & 0.079 & - & 186 & 80 & - \\
& $90^{\mathrm{c}}$ & 0.027 & 0.066 & 0.107 & 233 & 96 & 59 \\
\hline PE-32,32 & $0^{\mathrm{a}}$ & 0.045 & 0.108 & - & 140 & 58 & - \\
& $100^{\mathrm{b}}$ & 0.036 & 0.078 & - & 173 & 81 & - \\
& $102^{\mathrm{c}}$ & 0.028 & 0.063 & 0.101 & 221 & 99 & 62 \\
\hline PE-48,48 & $0^{\mathrm{a}}$ & 0.046 & - & - & 137 & - & - \\
& $108^{\mathrm{b}}$ & 0.035 & 0.068 & - & 182 & 92 & - \\
& $110^{\mathrm{c}}$ & 0.030 & 0.054 & 0.090 & 210 & 116 & 74
\end{tabular}

${ }^{\mathrm{a}}$ Rapidly quenched ex-situ in ice water, ${ }^{\mathrm{b}}$ non-isothermally crystallized in DSC, $T$ is onset crystallization temperature on cooling at a nominal rate of $40^{\circ} \mathrm{C} / \mathrm{min}$, and ${ }^{\mathrm{c}}$ temperature of isothermal crystallization.

Lamellar structural details of rapidly quenched, non-isothermally crystallized, and isothermally crystallized long-spaced polyesters

Values of $X_{\mathrm{c}}$, obtained from the WAXD patterns and of $l_{\mathrm{c}}$, the core lamellae thickness, are tabulated in Table SI.3, as are values of linear crystallinity $(\phi)$ or level of crystallinity within the lamellae stack cluster (for ex. within a spherulite). $\phi$ was calculated from the CF. ${ }^{1,2}$ Depending on how much the spherulites pervade the sample volume, $\phi$ is expected to be equal, slightly higher, or higher than the overall (volume-based) crystallinity determined by peak-deconvolution of WAXD patterns $\left(X_{\mathrm{c}}\right)$. For rapidly quenched LSAPEs, the spherulites are likely not volume filled throughout the sample, and as shown in the Table, $\phi>X_{\mathrm{c}}$. Therefore, the values estimated for the thickness of crystalline layers from Lorentz-corrected data (calculated as $L_{\mathrm{LC}}$ multiplied by $X_{\mathrm{c}}$ ) are also somewhat lower than $l_{\mathrm{c}}$, calculated using the $\mathrm{CF}$ (as $L_{\mathrm{CF}}$ multiplied by $\phi$ ). As shown, the estimates for crystal thickness using Lorentz-correction and using the correlation function are more agreeable for isothermally (better) crystallized samples. 
Table SI.3. Lamellar structural details of rapidly quenched, non-isothermally crystallized, and isothermally crystallized long-spaced polyesters analyzed by SAXS/WAXD and the normalized onedimensional correlation function $\gamma(r)(\mathrm{CF})$

\begin{tabular}{|c|c|c|c|c|c|c|c|c|c|}
\hline \multirow[b]{2}{*}{ Sample } & \multirow[b]{2}{*}{ Preparation } & \multirow[b]{2}{*}{$\begin{array}{c}T \\
\left({ }^{\circ} \mathrm{C}\right)\end{array}$} & \multicolumn{3}{|c|}{ Lorentz-Corrected SAXS } & \multicolumn{4}{|c|}{$\mathrm{CF}(\gamma(r))$} \\
\hline & & & $\begin{array}{c}X_{c} \\
(\text { WAXD) }\end{array}$ & $\begin{array}{l}L_{L C} \\
(\AA)^{\mathrm{e}}\end{array}$ & $\begin{array}{c}L_{L C} \times X_{C} \\
(\AA)\end{array}$ & $\phi^{\mathbf{f}}$ & $\begin{array}{l}L_{C F} \\
(\AA)^{\mathrm{g}}\end{array}$ & $\begin{array}{c}l_{c} \\
(\AA)^{\mathbf{h}}\end{array}$ & $l_{c} / d$ \\
\hline \multirow{3}{*}{ PE-18,18 } & Quenched $^{\text {a }}$ & 0 & 0.41 & 135 & 55 & 0.57 & 126 & 72 & $3.5^{\mathrm{i}}$ \\
\hline & Non-Iso ${ }^{b}$ & 87 & 0.58 & 172 & 100 & 0.64 & 158 & 102 & 4.9 \\
\hline & Isothermal $^{\mathrm{c}}$ & 90 & 0.57 & 199 & 113 & 0.71 & 184 & 131 & 6.3 \\
\hline \multirow{3}{*}{ PE-19,19 } & Quenched $^{\mathrm{a}}$ & 0 & 0.44 & 147 & 65 & 0.66 & 136 & 90 & $4.1^{\mathrm{i}}$ \\
\hline & Non-Iso ${ }^{b}$ & 88 & 0.60 & 186 & 111 & 0.70 & 172 & 120 & 5.5 \\
\hline & Isothermal $^{\mathrm{c}}$ & 90 & 0.55 & 233 & 127 & 0.74 & 213 & 157 & 7.2 \\
\hline \multirow{3}{*}{ PE-32,32 } & Quenched $^{\mathrm{a}}$ & 0 & 0.46 & 140 & 65 & 0.59 & 129 & 76 & $2.1^{\mathrm{i}}$ \\
\hline & Non-Iso ${ }^{b}$ & 100 & 0.62 & 173 & 103 & 0.65 & 165 & 107 & 3.0 \\
\hline & Isothermal $^{\mathrm{c}}$ & 102 & 0.65 & 221 & 137 & 0.68 & 212 & 143 & 4.1 \\
\hline \multirow{3}{*}{ PE-48,48 } & Quenched $^{\text {a }}$ & 0 & 0.50 & 137 & 68 & 0.64 & 129 & 83 & $1.7^{\mathbf{j}}$ \\
\hline & Non-Iso ${ }^{b}$ & 108 & 0.62 & 182 & 113 & 0.72 & 174 & 125 & 2.6 \\
\hline & Isothermal $^{\mathrm{c}}$ & 110 & 0.70 & 210 & 148 & 0.73 & 206 & 150 & 3.1 \\
\hline
\end{tabular}

${ }^{a}$ Rapidly quenched in ice water, ${ }^{b}$ non-isothermally crystallized in DSC, $T$ is onset crystallization temperature on cooling at $40^{\circ} \mathrm{C} / \mathrm{min}$, and ${ }^{\mathrm{c}}$ temperature of isothermal crystallization $T_{c}$, ${ }^{\mathrm{d}}$ level of crystallinity evaluated from WAXD patterns, ${ }^{\mathrm{e}}$ long spacing evaluated from the first correlation peak (as $\left.L_{\mathrm{LC}}=2 \pi / q\right)$ of Lorentz-corrected SAXS patterns, ${ }^{\mathrm{f}}$ linear crystallinity from correlation function (CF), ${ }^{\mathrm{g}}$ long spacing from $\mathrm{CF},{ }^{\mathrm{h}}$ crystal thickness from $\mathrm{CF},{ }^{\mathrm{i}}$ mixed layered and unlayered crystals. ${ }^{\mathrm{j}}$ unlayered crystals. 

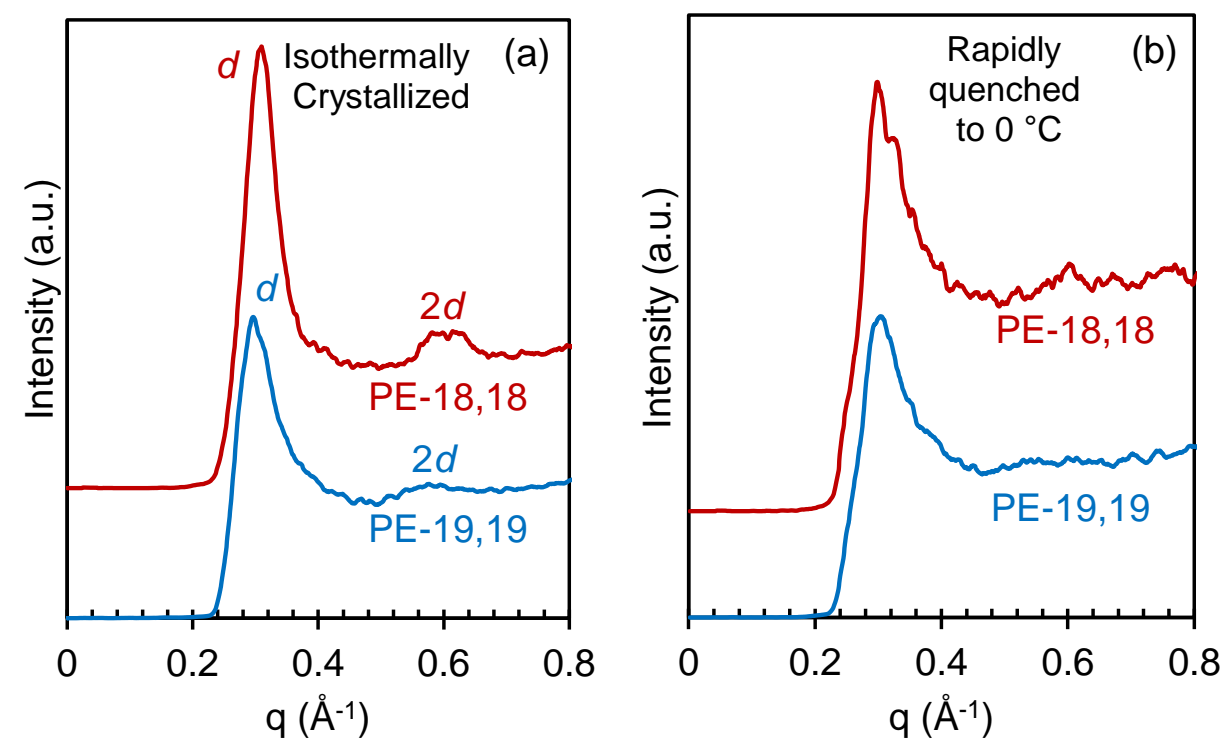

Figure SI.1. Low $q$ portion of WAXD diffractograms for PE-18,18 (red) and PE-19,19 (blue) after (a) isothermal crystallization at $T_{c}=92{ }^{\circ} \mathrm{C}$ and (b) rapid quenching to $T_{q}=0{ }^{\circ} \mathrm{C}$. Data have been vertically shifted for clarity. The second order layer peak is indicated by $2 d$ in (a), and has values of $q \sim 0.575 \AA^{-1}$ and $\sim 0.607 \AA^{-1}$ for PE-19,19 and PE-18,18 respectively.

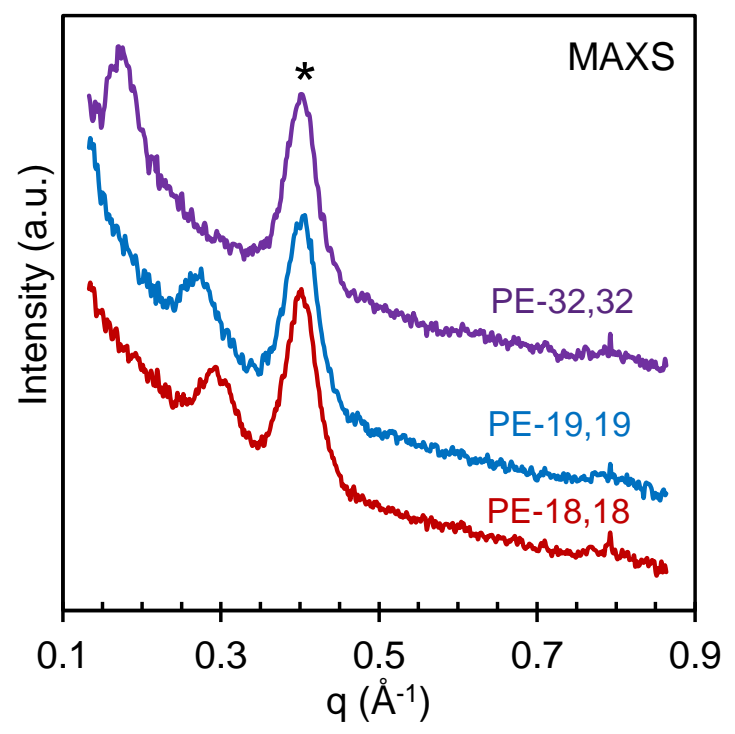

Figure SI.2. Middle-angle X-ray scattering (MAXS) patterns collected at the Advanced Photon Source of Argonne National Laboratory for PE-18,18 (red), PE-19,19 (blue), and PE-32,32 (purple) quenched from the melt to room temperature. The peak labeled with an asterisk at $q=$ $0.4 \AA^{-1}$ is related to the aluminum in which the sample was held. The layer peak is observed at $q$ $=0.292,0.272$, and $0.177 \AA^{-1}$ for PE-18,18, PE-19,19, and PE-32,32, respectively. 

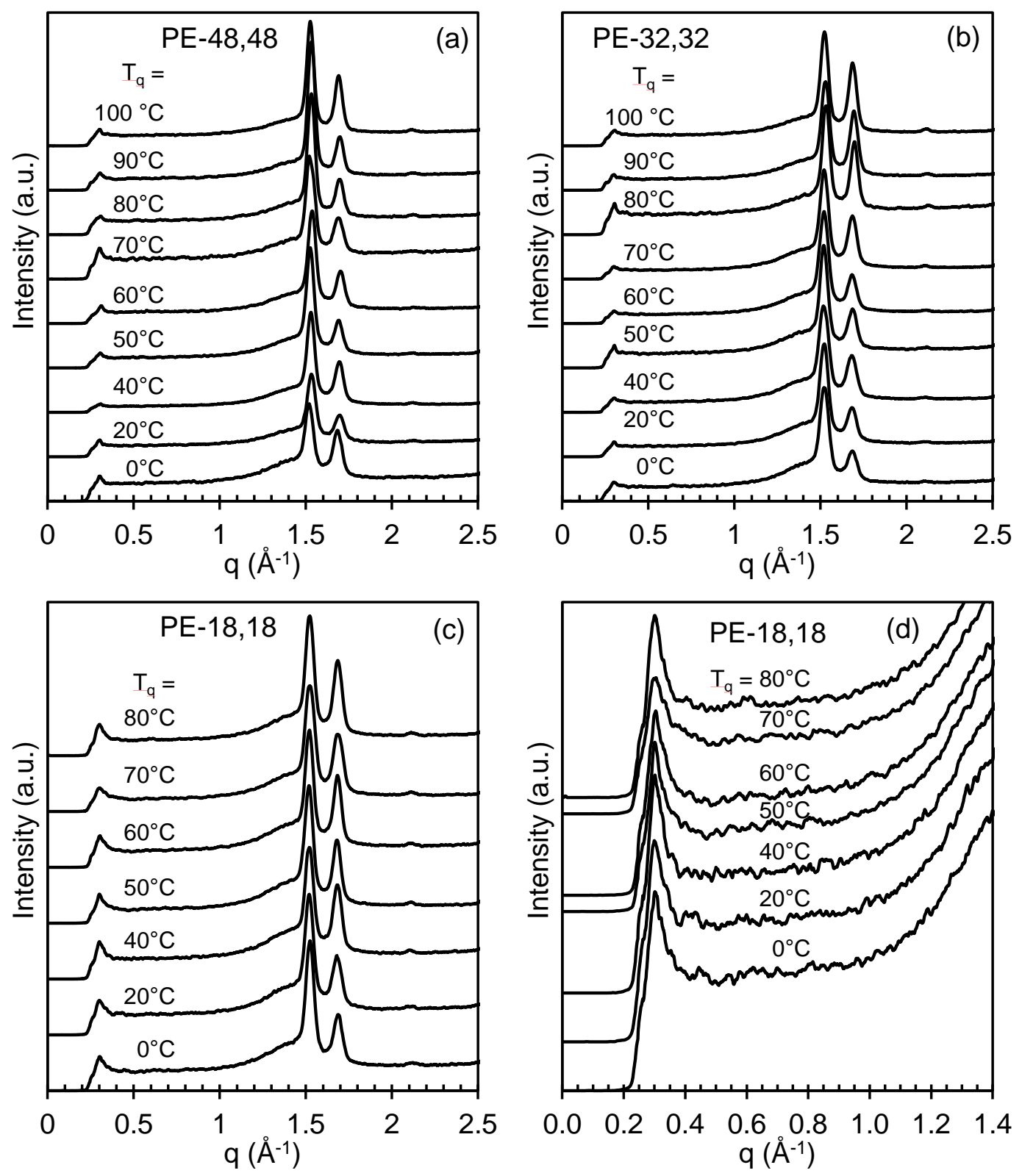

Figure SI.3. WAXD for PE-48,48 (a), PE-32,32 (b), and PE-18,18 (c, d) samples rapidly quenched to the indicated temperatures. (d) is an inset of the low $q$ region of (c). Data have been normalized by their total area for ease of comparison and vertically shifted for clarity. 


\section{Variation of level of crystallinity and crystal thickness with $T_{q}$}

Figure SI.4 shows the variation of $X_{\mathrm{c}}$ obtained from WAXD patterns and $l_{\mathrm{c}}$ from the CF applied to the data of Figure 5, both with increasing $T_{\mathrm{q}}$. As expected, there are no changes in the WAXD patterns with increasing $T_{\mathrm{q}}$ (Figure SI.3) and only a small and gradual increase of $X_{\mathrm{c}}$ from $\sim 45 \%$ to $60 \%$ is observed for all polyesters (Figure SI.4a). A sudden increase in $l_{\mathrm{c}}$ at the transition between both structures is also not observed. Prior to formation of the more symmetric layered structure, at $T_{\mathrm{q}}<60^{\circ} \mathrm{C}$, all polyesters have an $l_{\mathrm{c}}$ of $\sim 75-85 \AA$, as shown in Figure SI.4b, which is

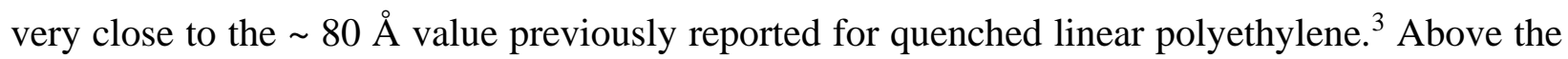
transition, $l_{c}$ shows a small increase from 85 to $95 \AA$. The steeper increase for PE-32,32 is associated with the higher thicknesses expected for crystals formed at temperatures $>80{ }^{\circ} \mathrm{C}$ near the isothermal crystallization range for this sample.
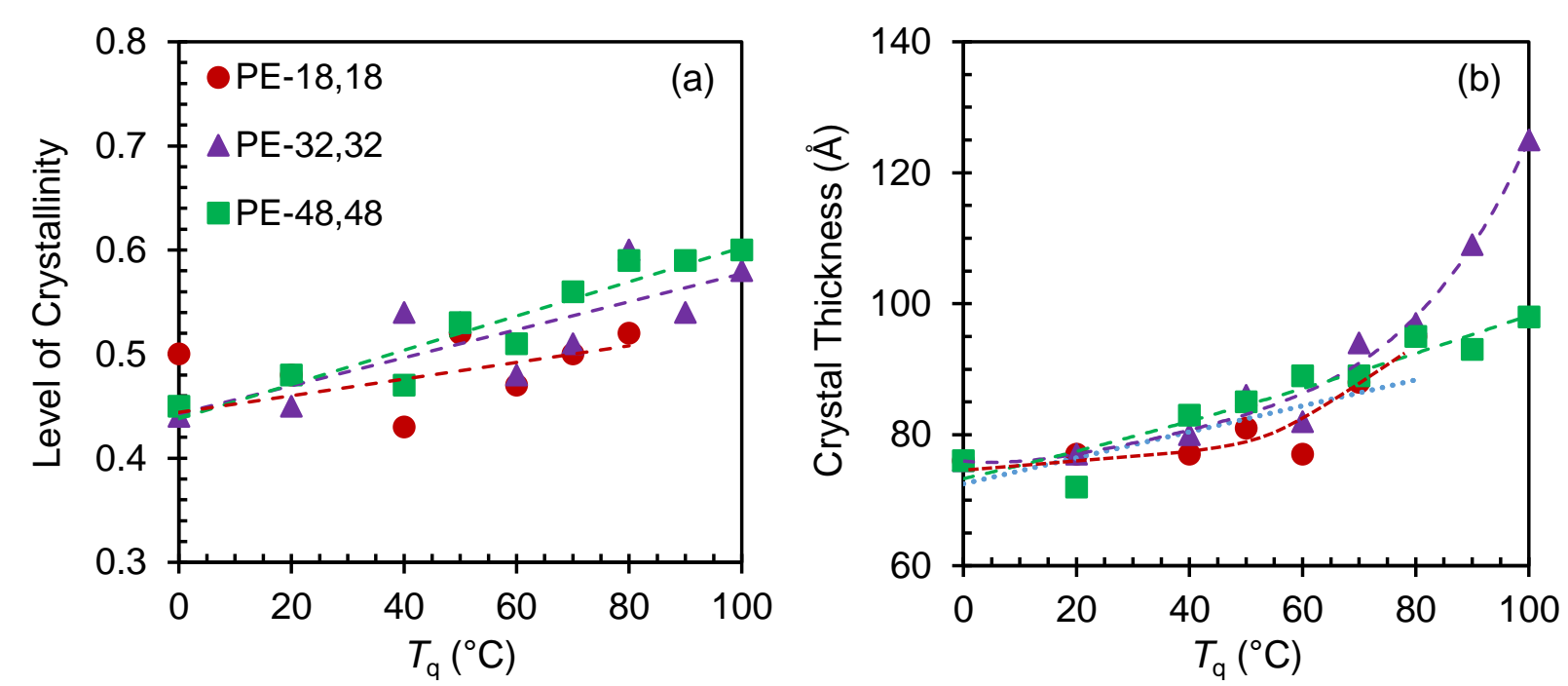

Figure SI.4. Level of crystallinity, $X_{\mathrm{c}}$ (a) and crystal thickness, $l_{\mathrm{c}}$ (b) as a function of the quenching temperature $T_{q}$ for PE-18,18 (red circles), PE-32,32 (purple triangles), and PE-48,48 (green squares). Dashed lines joining the experimental data are added only to guide the observed trends. 

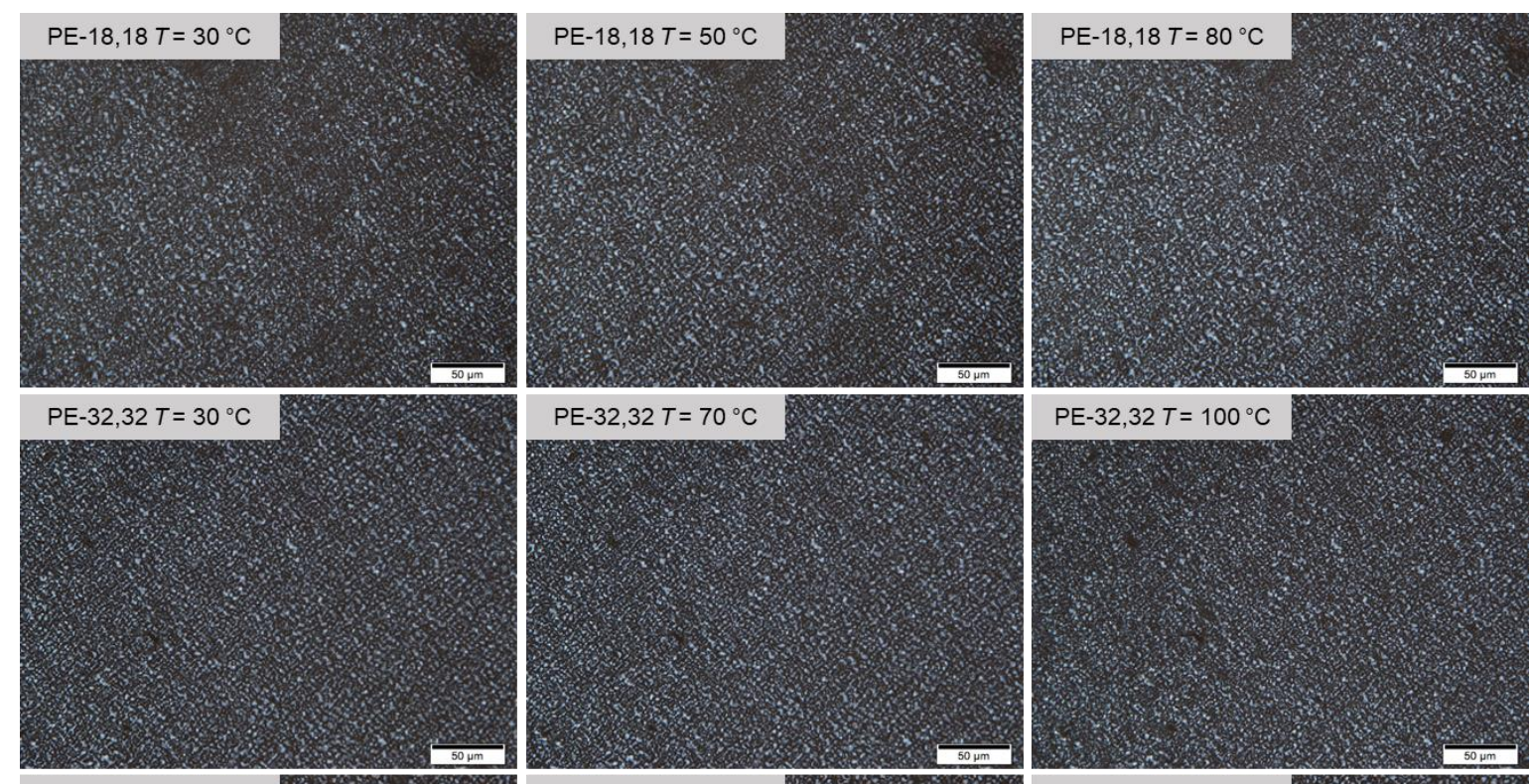

$\mathrm{PE}-32,32 T=100^{\circ} \mathrm{C}$

$\mathrm{PE}-48,48 \mathrm{~T}=30^{\circ} \mathrm{C}$

PE- $48,48 T=70^{\circ} \mathrm{C}$
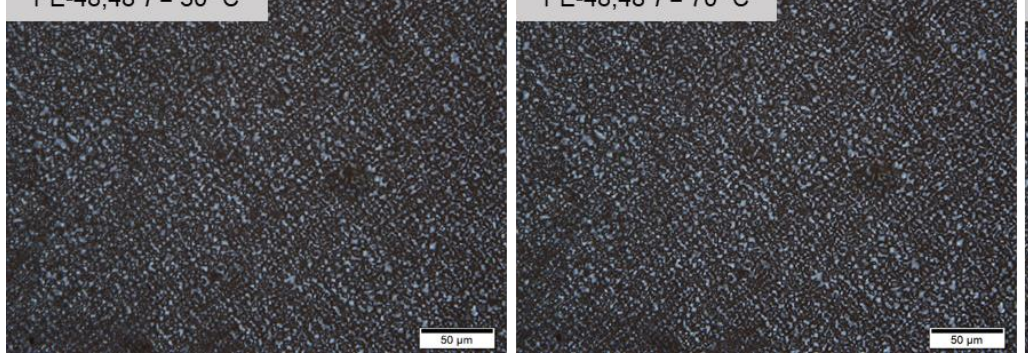

$\mathrm{PE}-48,48 \mathrm{~T}=100^{\circ} \mathrm{C}$

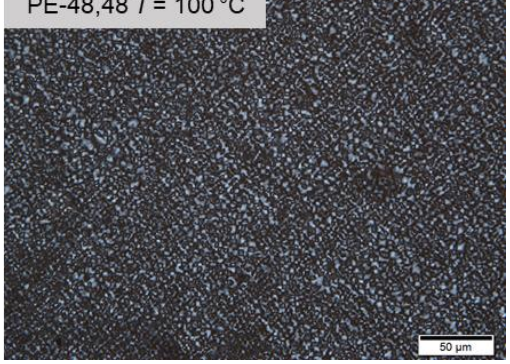

Figure SI.5. Polarized optical micrographs collected on heating samples of PE-18,18 (top), PE32,32 (middle), and PE-48,48 (bottom) that were first rapidly quenched to $0{ }^{\circ} \mathrm{C}$. The temperature in each micrograph indicates the temperature at which the image was collected (heating from left to right). Scale bars represent $50 \mu \mathrm{m}$. 

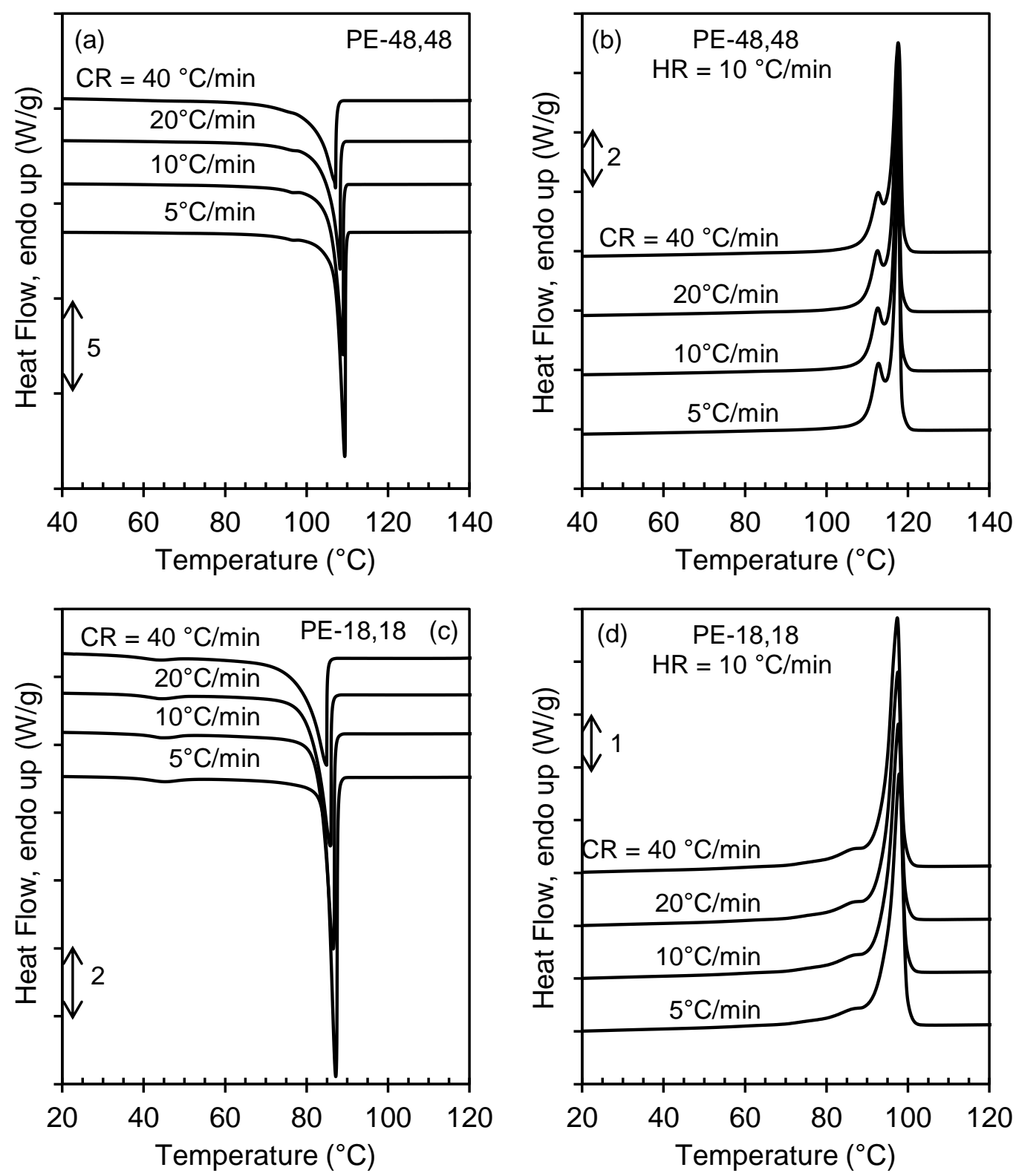

Figure SI.6. DSC crystallization exotherms collected at the indicated cooling rates, and subsequent melting endotherms collected at $10{ }^{\circ} \mathrm{C} / \mathrm{min}$ for PE-48,48 (a, b) and PE-18,18 (c, d). Exotherms have been normalized to a rate of $10{ }^{\circ} \mathrm{C} / \mathrm{min}$, and data have been vertically shifted for clarity. 


\section{Crystallization and Melting of LSAPEs using Fast Scanning Calorimetry}

To further expand the range of cooling rates accomplished in-situ, fast scanning calorimetry (FSC) was employed in addition to classical DSC. A Mettler Toledo Flash DSC 1 connected to a Huber TC100 intracooler was used for this purpose. FSC sensors were conditioned and corrected according to manufacturer specifications prior to sample loading. The sample was positioned within the FSC sensor with the help of a Leica M60 microscope equipped with a CCD IC90 camera See as an example Figure SI.7. Samples were brought to $\sim 30{ }^{\circ} \mathrm{C}$ above the final observed melting and held for $1 \mathrm{~s}$ to erase thermal history, before cooling at rates of 100, 500, $1000,2000,3000$, and $4000 \mathrm{~K} / \mathrm{s}$ to observe the crystallization exotherm. After crystallization, the samples were heated at $100 \mathrm{~K} / \mathrm{s}$ to observe the melting endotherm.

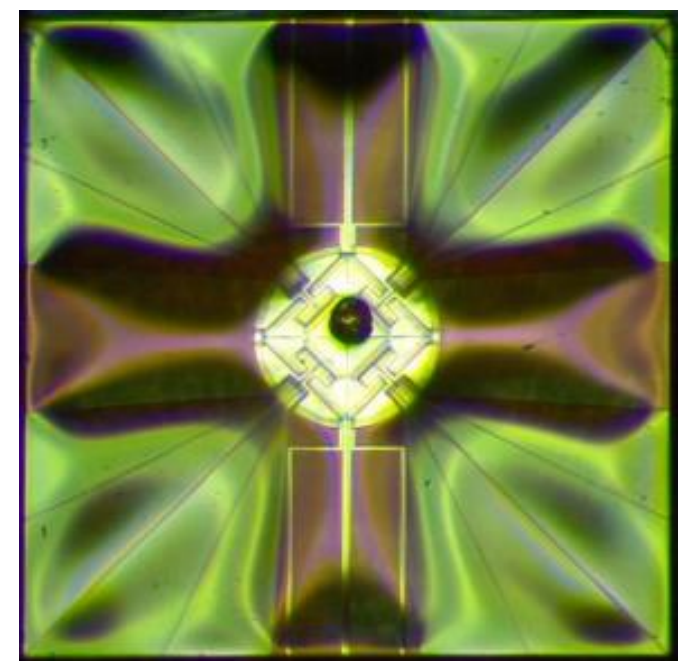

Figure SI.7. Optical microscopy image of PE-18,18 on an FSC sensor (height $=$ width $=2 \mathrm{~mm}$ ). 
Figure SI.8 shows crystallization exotherms collected on cooling at the indicated rates and subsequent melting endotherms collected at a rate of $100 \mathrm{~K} / \mathrm{s}$ for PE-48,48 (a and b) and PE18,18 (c and d). In Figure SI.8a and SI.8c, the $T_{\mathrm{c}}$ by classical DSC at $10{ }^{\circ} \mathrm{C} / \mathrm{min}$ is indicated by the red line. It is clear that with increasing cooling rate from 100 to $4000 \mathrm{~K} / \mathrm{s}(6000-240,000$ ${ }^{\circ} \mathrm{C} / \mathrm{min}$ ) the onset of the crystallization temperature decreases substantially, from 96 to $78{ }^{\circ} \mathrm{C}$ in PE-48,48 and from 80 to $59{ }^{\circ} \mathrm{C}$ in PE-18,18. However, this decrease in crystallization temperature does not translate to any change in the melting endotherms. To explain this melting invariance we must consider that in order to form the unlayered phase, crystallization would need to be suppressed until a temperature at which the unlayered phase can form. In the case of PE-48,48, this temperature would be about $60{ }^{\circ} \mathrm{C}$ and for PE-18,18 it would be about $50{ }^{\circ} \mathrm{C}$ (Figures 5 and 7). Even at the fastest rate possible by FSC of $4000 \mathrm{~K} / \mathrm{s}$, crystallization begins at $78{ }^{\circ} \mathrm{C}$ for PE-48,48 and at $\sim 59{ }^{\circ} \mathrm{C}$ for PE-18,18. Thus, it seems that even a rate of $4000 \mathrm{~K} / \mathrm{s}$ is insufficient to bypass the crystallization of the layered structure in these LSAPEs, and furthermore that it is not possible to replicate the results of ex-situ quenching using FSC. Manually fast quenching a relatively thin sample from the melt is the most effective route to form the unlayered structure in the LSAPEs. 

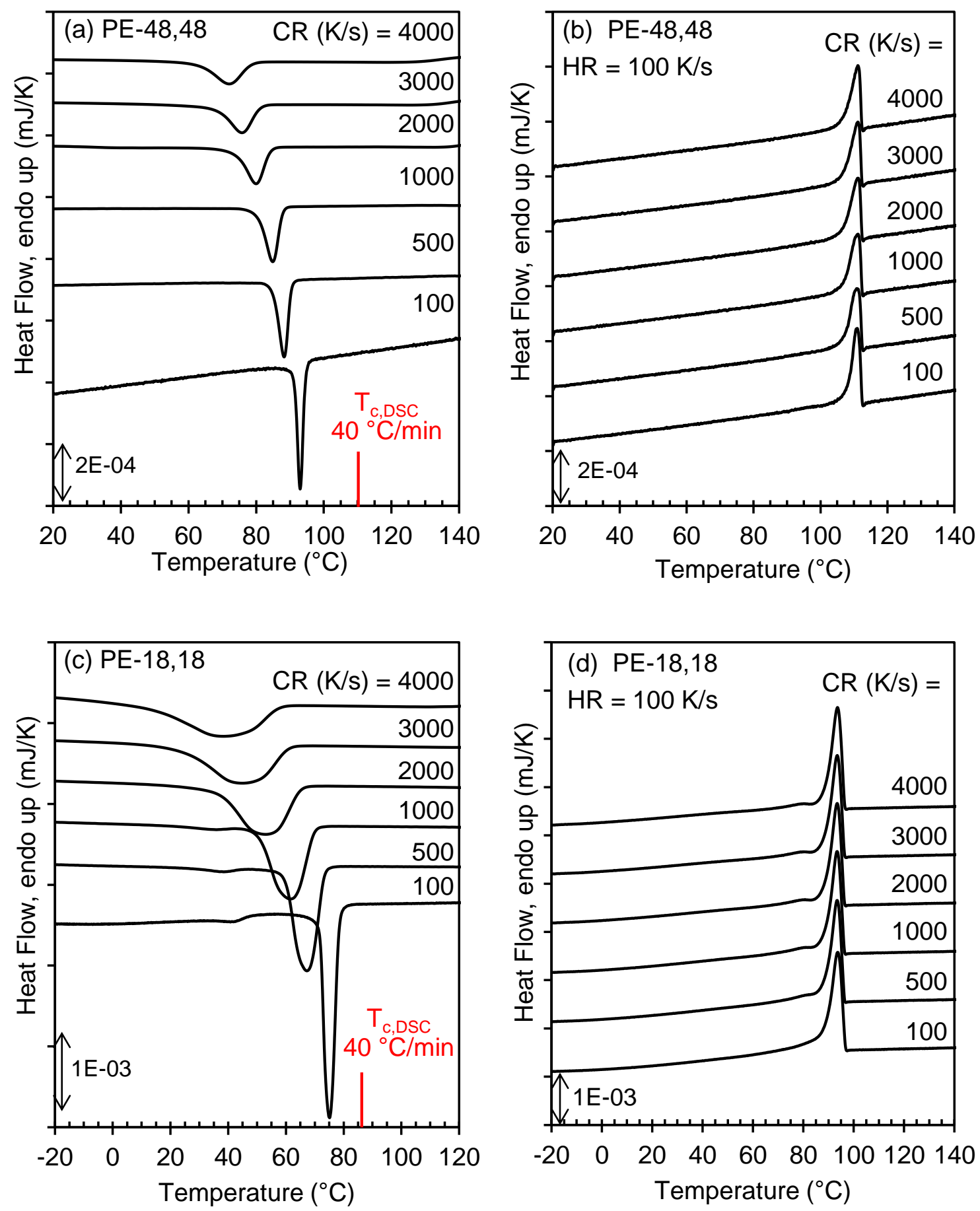

Figure SI.8. FSC crystallization exotherms for (a) PE-48,48 and (c) PE-18,18 on cooling at the indicated rates: 100, 500, 1000, 2000, 3000, or $4000 \mathrm{~K} / \mathrm{s}$ and corresponding melting endotherms for (b) PE-48,48 and (d) PE-18,18 collected on heating at $100 \mathrm{~K} / \mathrm{s}$. Data have been normalized by heating rate and vertically shifted for clarity. 

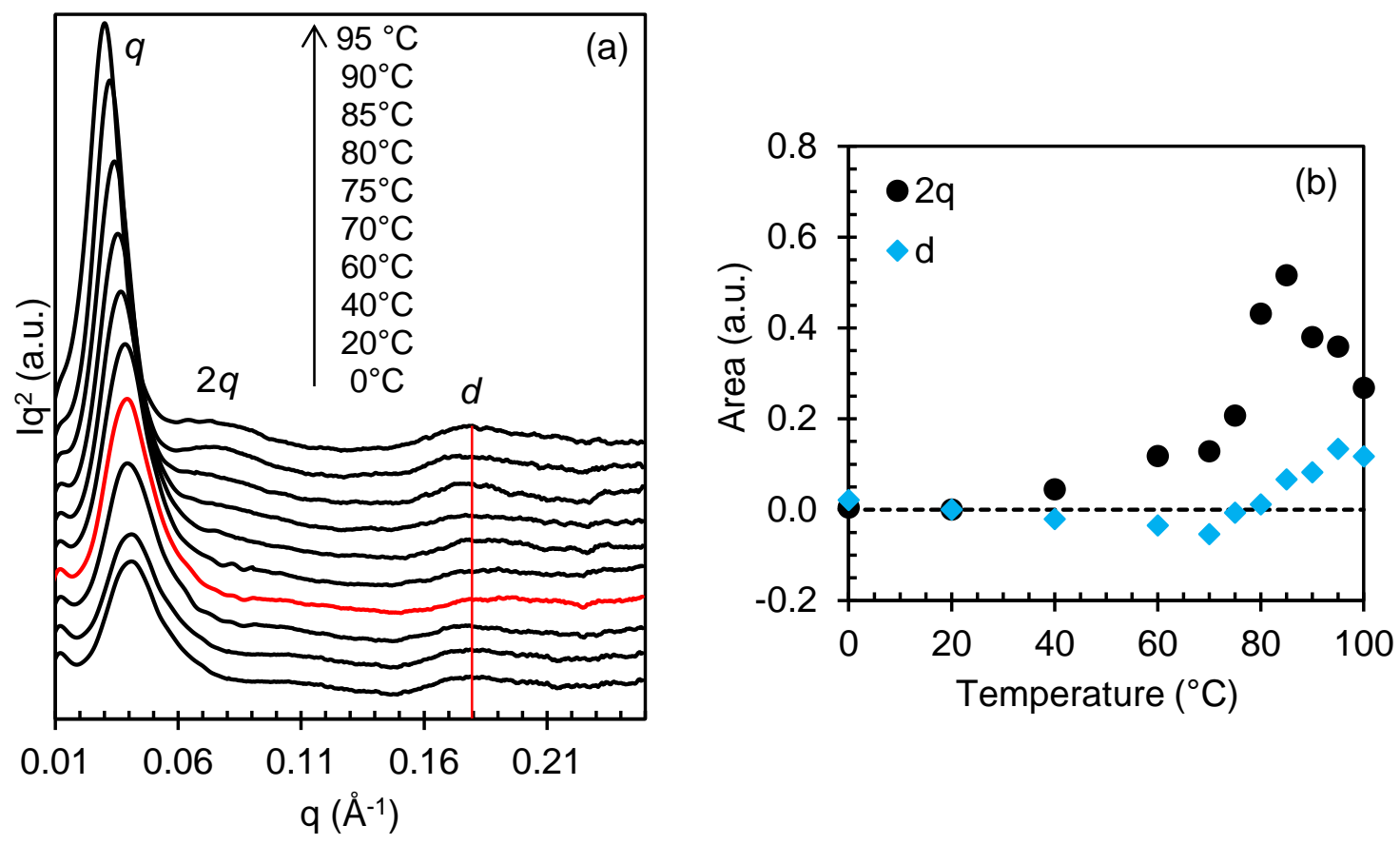

Figure SI.9. (a) In-situ Lorentz-corrected SAXS patterns collected at the indicated temperatures upon heating an unlayered sample of PE-32,32 which was fast quenched to $0{ }^{\circ} \mathrm{C}$. The location of the ester layer peak, $d$, is indicated by the red, vertical line. Data have been shifted vertically for clarity. (b) Quantification of the area of the second order long period (2q, black circles) and ester layer peak ( $d$, blue diamonds) as a function of temperature with respect to the pattern at $0{ }^{\circ} \mathrm{C}$. The temperature at which the area of $2 q$ begins to increase is highlighted with the red diffractogram in (a).

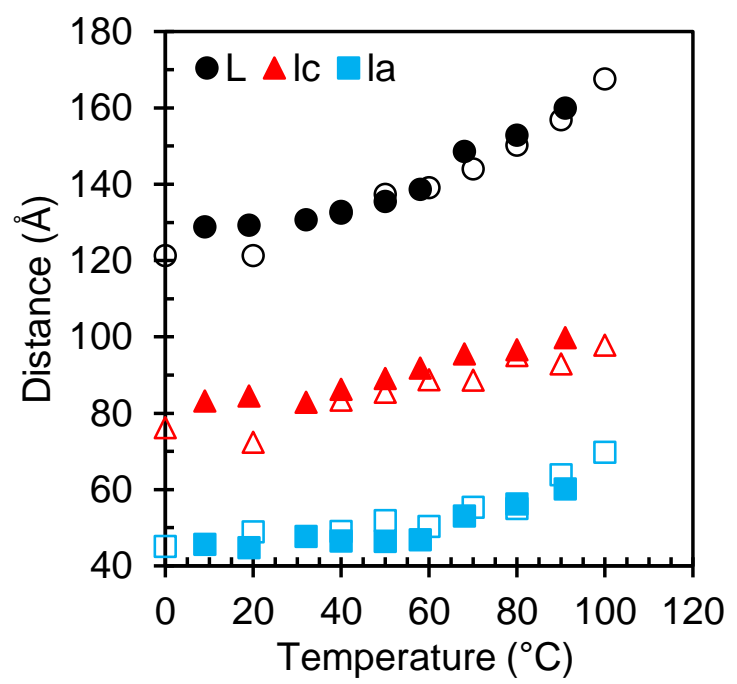

Figure SI.10. Long period (black circles, $L$ ), crystal thickness (red triangles, $l_{c}$ ), and amorphous thickness (blue squares, $l_{a}$ ) determined for PE-48,48 as a function of temperature from in-situ SAXS collected on heating (closed symbols) and from SAXS collected after $e x$-situ quenching to each temperature (open symbols). 

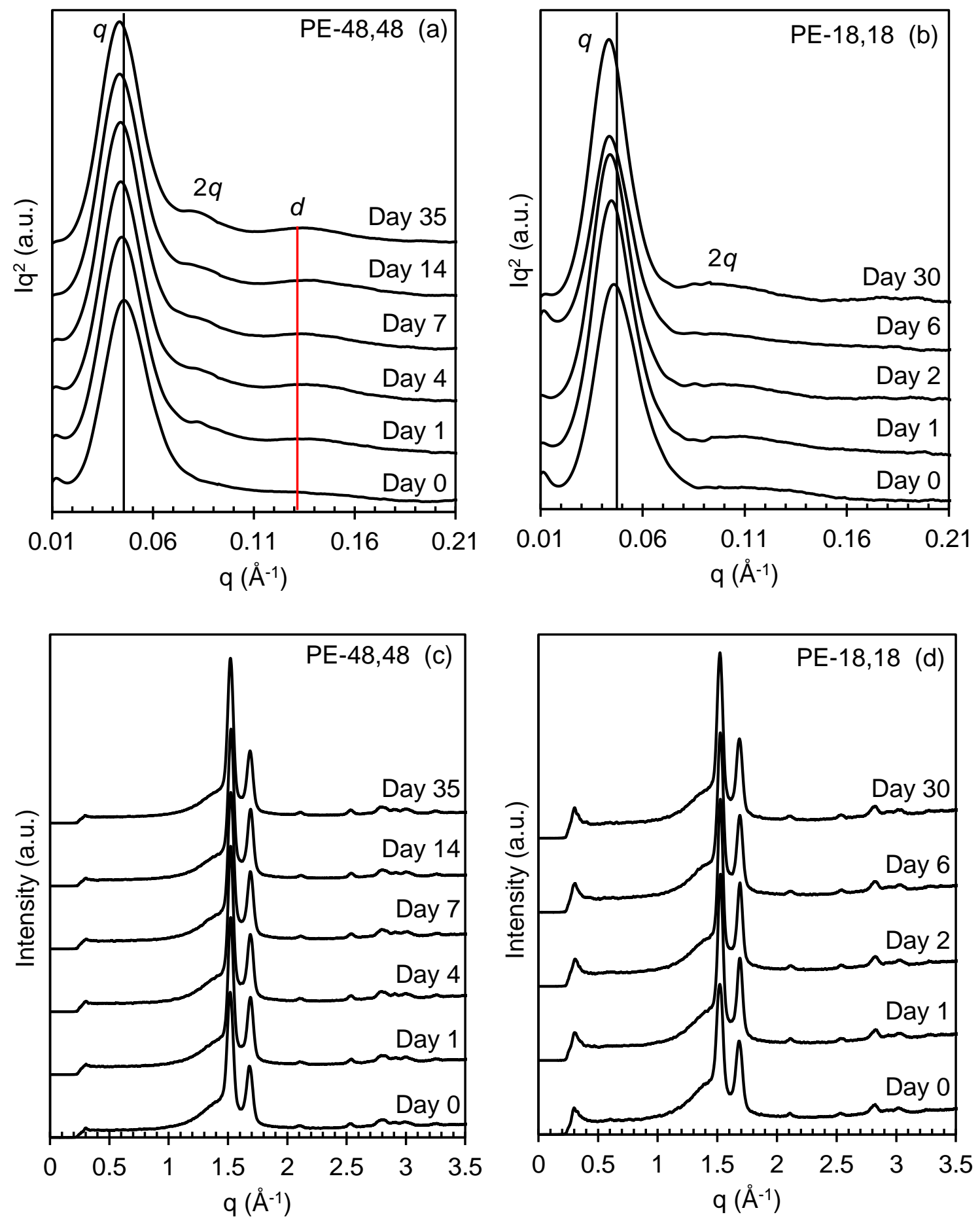

Figure SI.11. Lorentz-corrected SAXS (a-b) and WAXD (c-d) patterns for PE-48,48 (a and c) and PE-18,18 (b and d) obtained at room temperature after rapid quenching to $0{ }^{\circ} \mathrm{C}$ and subsequent annealing at $40{ }^{\circ} \mathrm{C}$ for the indicated durations of time. Vertical lines in a and b represent the long period and layer peaks. SAXS patterns have been normalized by their total area and vertically shifted for clarity. 

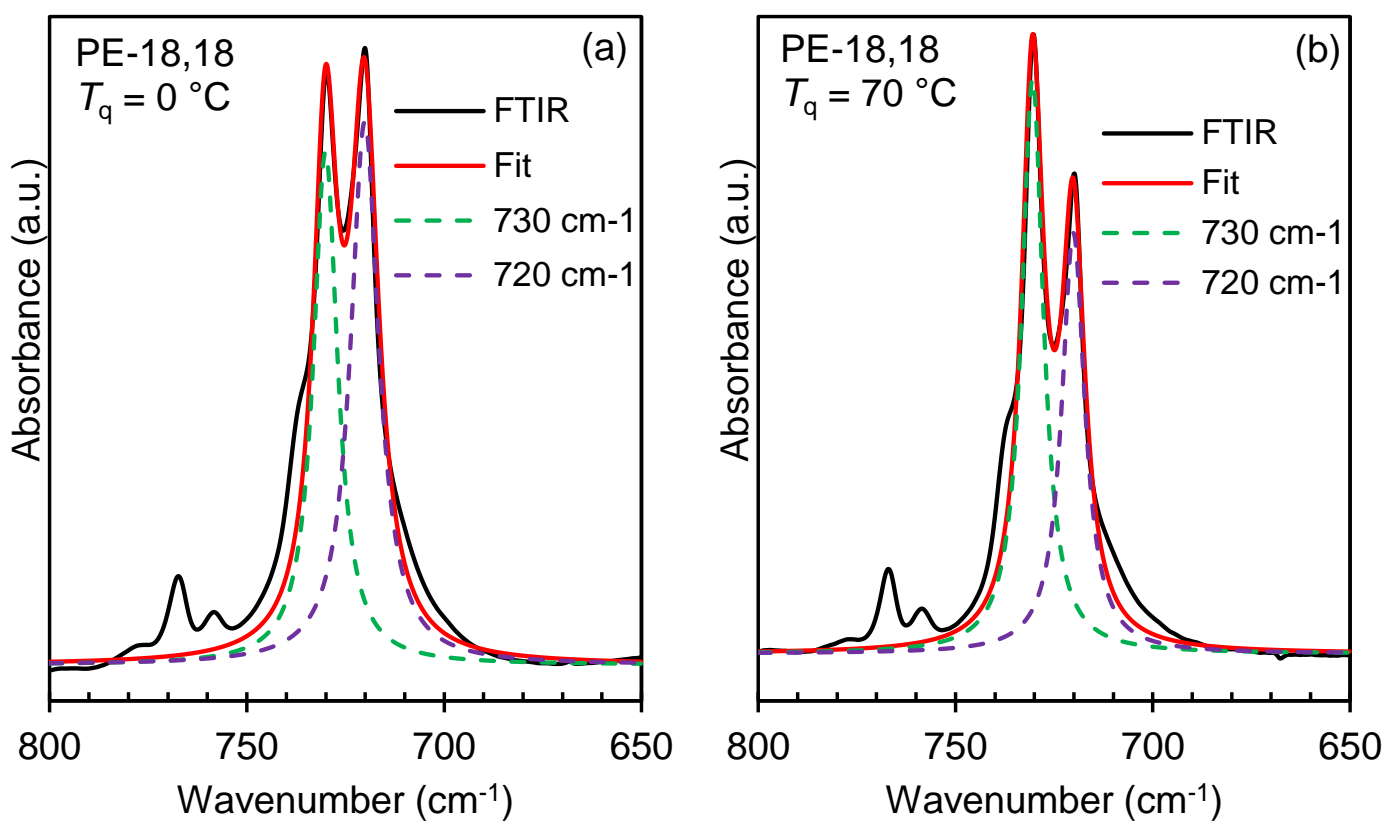

Figure SI.12. Peak deconvolution of the $\mathrm{CH}_{2}$ rocking bands observed at 730 and $720 \mathrm{~cm}^{-1}$ by room temperature FTIR for PE-18,18 prepared by rapid quenching to (a) $0{ }^{\circ} \mathrm{C}$ and (b) $70{ }^{\circ} \mathrm{C}$.

Table SI.4. Full-width at half-height (FWHH) in $\mathrm{cm}^{-1}$ of $\mathrm{C}=\mathrm{O}$ stretching and $\mathrm{CH}_{2}$ rocking bands by FTIR for quenched LSAPEs

\begin{tabular}{|c|c|c|c|c|c|c|c|}
\hline \multirow[t]{2}{*}{ Sample } & \multirow[t]{2}{*}{$T_{\mathrm{q}}\left({ }^{\circ} \mathrm{C}\right)$} & \multicolumn{2}{|c|}{$\begin{array}{c}1740 \mathrm{~cm}^{-1} \\
\mathrm{C}=\mathrm{O} \text { stretching }\end{array}$} & \multicolumn{2}{|c|}{$\begin{array}{c}730 \mathrm{~cm}^{-1} \\
\mathrm{CH}_{2} \text { rocking }\end{array}$} & \multicolumn{2}{|c|}{$\begin{array}{c}720 \mathrm{~cm}^{-1} \\
\mathrm{CH}_{2} \text { rocking }\end{array}$} \\
\hline & & FWHH & Ratio $^{\text {a }}$ & $\mathrm{FWHH}^{\mathrm{b}}$ & Ratio $^{a}$ & $\mathrm{FWHH}^{\mathrm{b}}$ & Ratio $^{a}$ \\
\hline \multirow[t]{2}{*}{ PE-18,18 } & 0 & 48 & \multirow{2}{*}{2.0} & 7.5 & \multirow{2}{*}{1.1} & 8.7 & \multirow{2}{*}{1.2} \\
\hline & 70 & 23 & & 6.7 & & 7.1 & \\
\hline \multirow[t]{2}{*}{ PE-32,32 } & 0 & 65 & \multirow{2}{*}{4.2} & 9.5 & \multirow{2}{*}{1.7} & 10 & \multirow{2}{*}{1.7} \\
\hline & 80 & 15 & & 5.6 & & 5.9 & \\
\hline \multirow[t]{2}{*}{ PE-48,48 } & 0 & 59 & \multirow{2}{*}{3.0} & 7.5 & \multirow{2}{*}{1.4} & 8.7 & \multirow{2}{*}{1.7} \\
\hline & 80 & 20 & & 5.6 & & 5.1 & \\
\hline
\end{tabular}

${ }^{\text {a }} \mathrm{FWHH}$ of band for $T_{\mathrm{q}}=0{ }^{\circ} \mathrm{C}$ divided by $\mathrm{FWHH}$ of band for $T_{\mathrm{q}}=70$ or $80{ }^{\circ} \mathrm{C}$, ${ }^{\mathrm{b}}$ After peak deconvolution. 


\section{References}

(1) Goderis, B.; Reynaers, H.; Koch, M. H. J.; Mathot, V. B. F. Use of SAXS and Linear Correlation Functions for the Determination of the Crystallinity and Morphology of Semi-Crystalline Polymers. Application to Linear Polyethylene. J. Polym. Sci. Part B Polym. Phys. 1999, 37 (14), 1715-1738. https://doi.org/10.1002/(SICI)1099-0488(19990715)37:14<1715::AIDPOLB15>3.0.CO;2-F.

(2) Zhang, X.; Zuo, X.; Ortmann, P.; Mecking, S.; Alamo, R. G. Crystallization of Long-Spaced Precision Polyacetals I: Melting and Recrystallization of Rapidly Formed Crystallites.

Macromolecules 2019, 52 (13), 4934-4948. https://doi.org/10.1021/acs.macromol.9b00922.

(3) Voigt-Martin, I. G.; Mandelkern, L. A Quantitative Electron-Microscopic Study of a Linear Polyethylene Fraction Crystallized at Different Temperatures. J. Polym. Sci. Polym. Phys. Ed. 1981, 19 (11), 1769-1790. https://doi.org/10.1002/pol.1981.180191109. 